\title{
COVID-19 quarantine in chronic kidney disease patients: A focus on sarcopenia traits
}

\section{Quarentena da COVID-19 em pacientes com doença renal crônica:} Um enfoque nas características de sarcopenia

\section{Authors}

Heitor Siqueira Ribeiro ${ }^{1}$ iD

Kenneth R. Wilund ${ }^{2}$

Ricardo Moreno Lima'

'Universidade de Brasília, Faculdade de Educação Física, Brasília, DF, Brasil.

${ }^{2}$ University of Illinois at UrbanaChampaign, Department of Kinesiology and Community Health, Urbana, IL, USA.
Submitted on: 09/16/2020

Approved on: 01/11/2021.

Correspondence to:

Heitor Siqueira Ribeiro.

E-mail: heitorsiqueira95@gmail.com DOI: https://doi.org/10.1590/21758239-JBN-2020-0201

\section{Dear Editor,}

Recently, the Brazilian Journal of Nephrology (BJN) published a supplementary issue regarding the Coronavirus Disease 2019 (COVID-19) impact on clinical nephrology routine, with a special focus on people with chronic kidney disease $(\mathrm{CKD})^{1}$. We congratulate the $\mathrm{BJN}$ for the initiative, as it will have a high impact on COVID-19 management for nephrology professionals. Nonetheless, we would like to call attention to a negligence about the COVID-19 quarantine impact on physical function and musculoskeletal health, which has not been introduced and discussed by the BJN. levels of sedentary behavior, which increases across the stages of the disease. Wilkinson et al. observed that walking is the most popular form of physical activity of people with $\mathrm{CKD}^{2}$, so greater sedentary behavior is expected as a consequence of COVID-19 quarantine. Hence, losses in muscle mass and strength are also expected, which is known to negatively affect physical function in this population ${ }^{3}$. Moreover, Cheval et al. found that an increase in sedentary behavior during COVID-19 quarantine was associated with poorer physical health, mental health, and subjective vitality in general subjects ${ }^{4}$.
People with CKD usually have high
Sarcopenia is defined by an age-related decline in muscle mass, strength, and physical function. It is known that people with CKD are at higher risk for sarcopenia, which is related to a systemic catabolic state, higher protein energy wasting, and other metabolic disorders ${ }^{5}$. As seen in Figure 1, quarantine-related muscular disuse and inadequate dietary intake may potentially increase sarcopenia signs among people with $\mathrm{CKD}$, a population that already presents with reduced functional reserve.

People with CKD not yet in hemodialysis (HD) may be experiencing an even greater impact from quarantine than HD patients. In general, HD patients are still attending their dialysis clinics for scheduled treatments, so social isolation may not have impacted their routines to the same extent. Conversely, non-dialysis CKD patients do not have the same constraints, and they are generally more physically active. Thus, quarantine and social isolation due to COVID-19 may have a greater impact on their current lifestyle. The duration of social distancing that will be required for high risk individuals is not known, but the longer it lasts, the greater the impact it will likely have on the development and progression of sarcopenia in people with CKD around the world. Related consequences

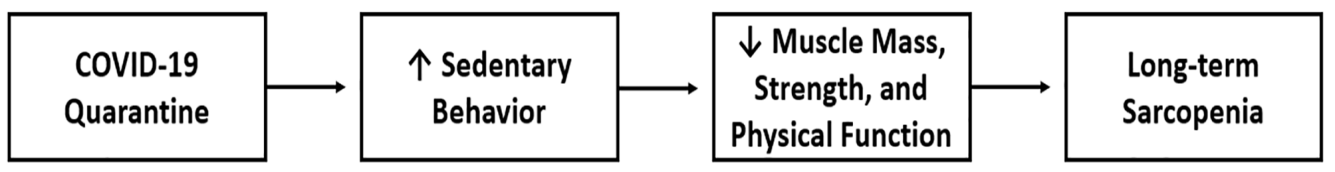

Figure 1. COVID-19 quarantine and its association with sarcopenia in chronic kidney disease patients. 
could include increases in cardiovascular events, hospitalization, progression to renal failure, mortality, and poor prognosis for kidney transplants. Thus, the
European Work Group on Sarcopenia in Older People (EWGSOP2 $)^{6}$ criteria should be used for screening and monitoring sarcopenia (Table 1), as well as SARC-F questionnaire in the absence of direct measures.

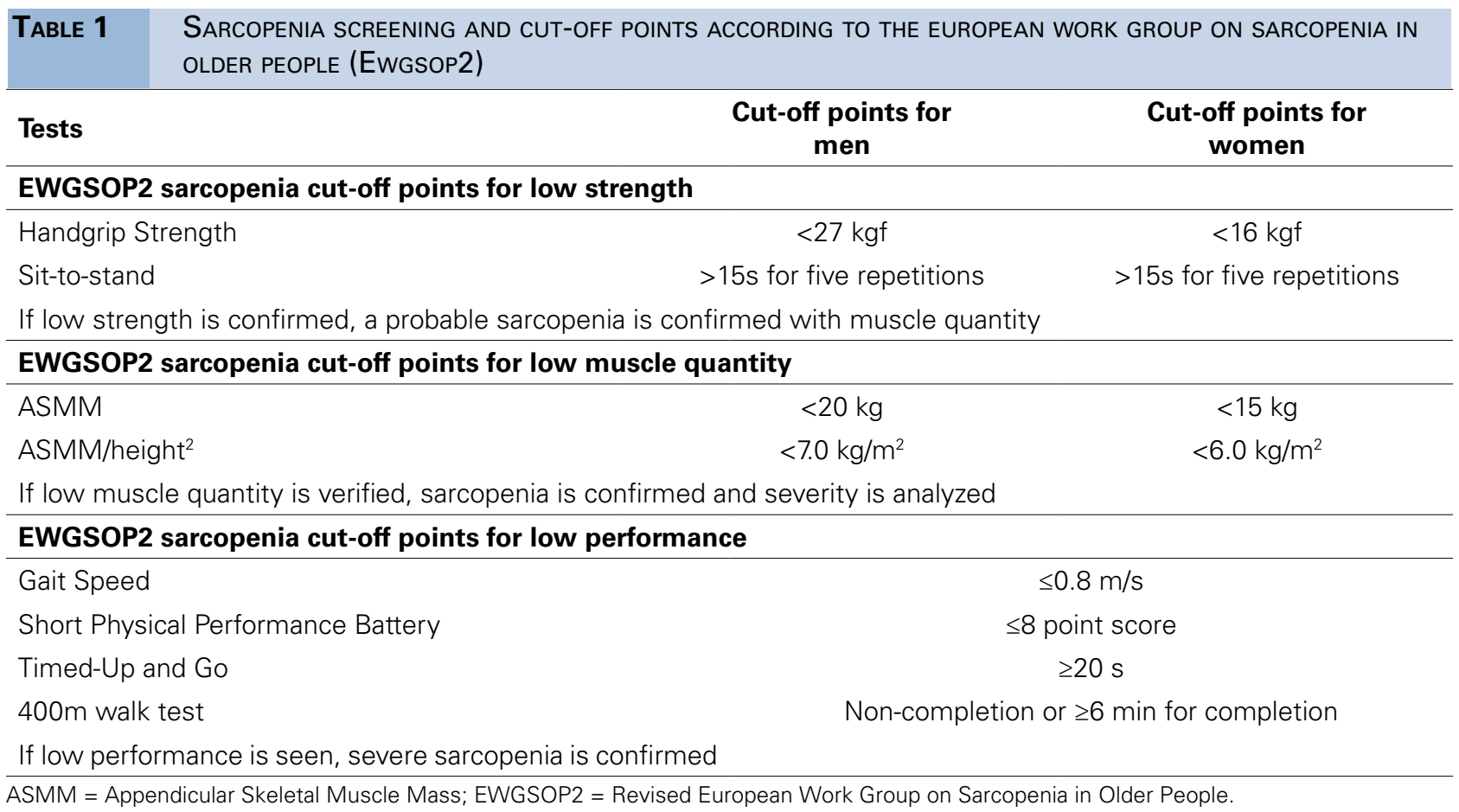

Health professionals involved in the management of CKD need to consider strategies in order to mitigate the adverse effects of quarantine and social distancing on physical activity and musculoskeletal health. Exercise and nutrition interventions can potentially attenuate these adverse effects. Therefore, we encourage patients of all CKD stages to maintain or engage an active lifestyle, as well as adequate dietary intake during COVID-19 quarantine. To make these interventions safe and feasible, we recommend two guides: Coronavirus Disease 2019: Quick Diet and Nutrition Guide for Patients With Chronic Kidney Disease (https://www.jrnjournal.org/ article/S1051-2276(20)30213-2/fulltext) and My Get Active Guide (http://move.bangor.ac.uk/get-active.php. en), both available in Portuguese and English versions.

\section{Authors' Contribution}

HSR: drafted and wrote the manuscript.

KRW and RML: reviewed and approved the final version.

\section{Conflict of InTEREST}

The authors have no conflicts of interest to declare.

\section{References}

1. Abreu AP, Riella MC, Nascimento MM. The Brazilian Society of Nephrology and the Covid-19 pandemic. Brazilian J Nephrol. 2020;42(2 Suppl 1):1-3. DOI: https://doi.org/10.1590/21758239-ibn-2020-s101

2. Wilkinson TJ, Clarke AL, Nixon DGD, Hull KL, Song Y, Burton JO, et al. Prevalence and correlates of physical activity across kidney disease stages: an observational multicentre study. Nephrol Dial Transplant. 2019 Nov;gfz235. DOI: https://doi. org/10.1093/ndt/gfz235

3. Morley JE, Kalantar-Zadeh K, Anker SD. COVID-19: a major cause of cachexia and sarcopenia?. J Cachexia Sarcopenia Muscle. 2020 Jun;11(4):1-3. DOI: https://doi.org/10.1002/ jcsm. 12589

4. Cheval B, Sivaramakrishnan H, Maltagliati S, Fessler L, Forestier C, Sarrazin P, et al. Relationships between changes in self-reported physical activity, sedentary behaviour and health during the coronavirus (COVID-19) pandemic in France and Switzerland. J Sports Sci. 2020 Oct 29; [Epub ahead of print]. DOI: https://doi.org/10.1080/02640414.2020.1841396

5. Moorthi RN, Avin KG. Clinical relevance of sarcopenia in chronic kidney disease. Curr Opin Nephrol Hypertens. 2017 May;26(3):219-28. DOI: https://doi.org/10.1097/ MNH.0000000000000318

6. Cruz-Jentoft AJ, Bahat G, Bauer J, Boirie Y, Bruyère $O$, Cederholm T, et al. Sarcopenia: revised European consensus on definition and diagnosis. Age Ageing. 2019 Jan;48(1):16-31. DOI: https://doi.org/10.1093/ageing/afy169 